\title{
Lymphocytic venulitis: an unusual association with microscopic colitis
}

\author{
D S Arora, T Mahmood, J I Wyatt
}

\begin{abstract}
A 79 year old man presented with occult gastrointestinal bleeds and anaemia for two years. He had received 40 units of blood over a period of one year, following which he had a subtotal colectomy as no definite cause of the bleeding was apparent. Macroscopically the colon appeared unremarkable. Light microscopy showed prominent lymphocytic venulitis in the proximal portion, gradually merging into lymphocytic and collagenous colitis distally.

(F Clin Pathol 1999;52:303-304)
\end{abstract}

Keywords: lymphocytic venulitis; collagenous colitis; lymphocytic colitis

Vasculitis of the intestinal tract is very rare. It occurs most often in association with other conditions, especially systemic vasculitis ${ }^{1}$ and inflammatory bowel disease. ${ }^{2}$ Isolated mesenteric venulitis is extremely rare but has been reported as a rare cause of intestinal ischaemia. $^{34}$

Collagenous and lymphocytic colitis are two related and recently described disorders, characterised by thickening of the subepithelial collagenous band and diffuse intraepithelial lymphocytic infiltration, respectively. ${ }^{5}$ These forms of microscopic colitis present most often with chronic watery diarrhoea. Colonoscopy is usually normal. ${ }^{5}$ There is an association with other diseases such as arthritis, ${ }^{6}$ coeliac disease, ${ }^{7}$ ulcerative colitis, ${ }^{8}$ and protein losing enteropathy. $^{9}$

We present a case of lymphocytic venulitis in association with microscopic colitis. To the best of our knowledge, this is the first case of such an association.

\section{Case report}

A 79 year old white man presented with anaemia, abdominal pain, dyspepsia, and bleeding from the rectum, requiring transfusion of 40 units of blood over the previous 15 months. Faecal occult blood was positive but full radiology including mesenteric angiography were all normal.

Previous medical history included duodenal ulcer, gout, left sided cerebrovascular accident, aortic stenosis, hypertension, glaucoma, and prostatic adenocarcinoma diagnosed in 1992, with bone metastases in 1995. As a result he was taking many drugs including aspirin, dipyridamole, nifedipine, flutamide, Honvan (tetrasodium fosfesterol), omeprazole, ferrous sulphate, and Frumil (frusemide plus amiloride).

A subtotal colectomy and ileorectal anastomosis was performed because of failing medical management of the bleeding.

\section{Pathological findings}

The specimen of subtotal colectomy was examined after formalin fixation. It consisted of $80 \mathrm{~cm}$ of colon together with $18 \mathrm{~cm}$ of terminal ileum and a $9 \mathrm{~cm}$ long appendix.
Department of Histopathology, St James's University Hospital, Beckett Street, Leeds LS9 7TF, UK

D S Arora

T Mahmood

J I Wyatt

Correspondence to: Dr Wyatt.

Accepted for publication 1 September 1998
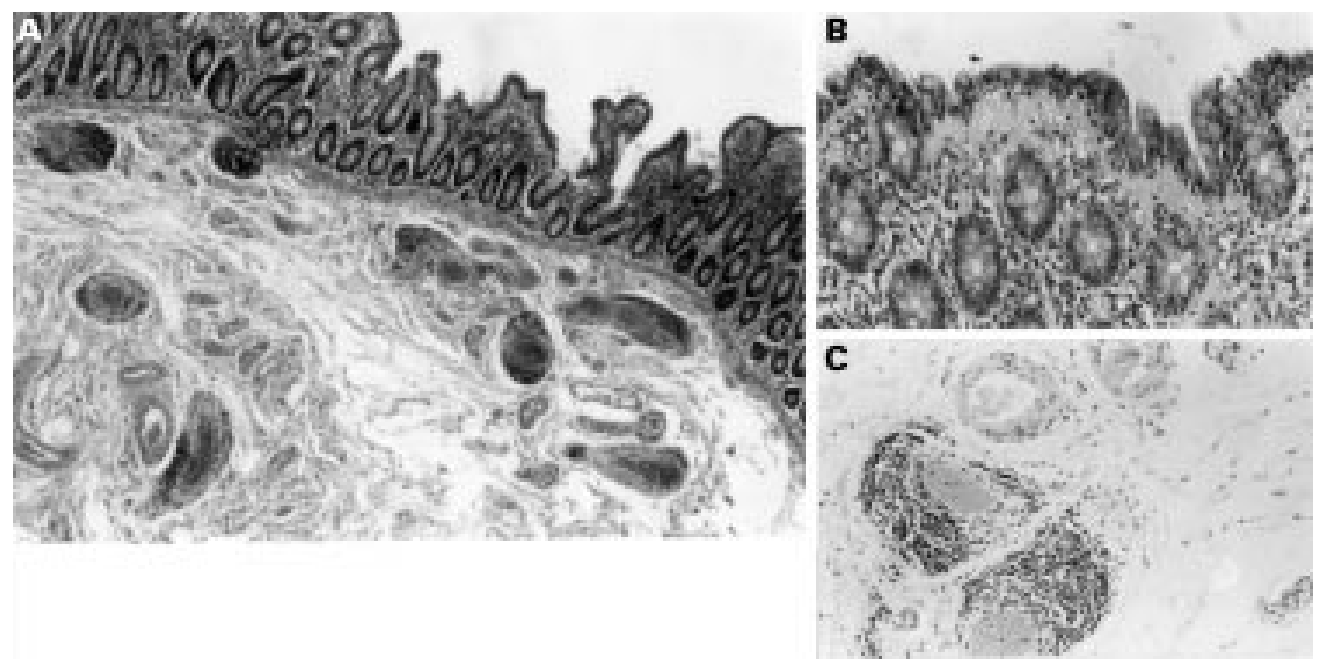

Figure 1 (A) Section from transverse colon showing overlapping features of lymphocytic and collagenous colitis in the mucosa and lymphocytic venulitis in the submucosa. (Haematoxylin and eosin (HEE); magnification $\times 21$.) (B) High power view of the mucosa shows an increase in lamina propria cellularity with an increase in intraepithelial lymphocytes (up to 20/100 epithelial cells) and thickening of the subepithelial collagen plate. (HEE; magnification $\times 106$.) (C) High power view of the submucosa showing intense infiltration of the walls of all submucosal veins by small lymphocytes. The arteries are unaffected. (HEEE; magnification $\times 106)$. 
There was a small caecal diverticulum but no ulceration or other macroscopic abnormality was identified.

Microscopically, the colonic mucosa showed features of lymphocytic colitis including an increase in lamina propria cellularity with an excess of intraepithelial lymphocytes (up to 20/100 epithelial cells). This was accompanied by thickening of the subepithelial collagen band to an average of 15 microns which increased to 20 microns in focal areas (fig 1B). There was no evidence of crypt distortion, active cryptitis, or crypt abscesses. No granulomas were seen.

The submucosa of the large bowel showed a dense perivenular inflammatory cell infiltrate composed of a monomorphic population of small lymphocytes. No nuclear pleomorphism or mitotic figures were seen to suggest angiocentric lymphoma. No neutrophils, plasma cells, or macrophages were present. The infiltrate involved only the submucosal veins, and the arteries were not affected by the infiltrate (fig 1C). However, a few vessels showed myointimal hyperplasia and reduplication of the elastic lamina. No thrombosis was seen in any vessel. The lymphocytic venulitis appeared mainly to involve the submucosal vessels; however, a lesser degree of serosal involvement was also seen. No ischaemic changes were seen in any of the widely sampled blocks.

Immunohistochemistry showed that both the intraepithelial and perivenular lymphocytes were mainly $\mathrm{T}$ cells. Only a few B cells were seen in the perivenular infiltrate.

The changes of lymphocytic venulitis were more prominent proximally, while those of collagenous and lymphocytic colitis were more prominent distally. However, a significant length of the transverse colon showed overlapping features of both conditions (fig 1A). The ileum and the resection margins appeared unremarkable.

Following surgery, the patient continued to suffer from rectal bleeding. This was clinically attributed to small bowel telangiectasia, although there was no tissue diagnosis to confirm this. He died two months after surgery.

\section{Discussion}

We present a case of intestinal lymphocytic venulitis in association with lymphocytic and collagenous colitis, representing the cooccurrence of two rare and recently described histological entities. To the best of our knowledge this is the first case of an association of these two rare entities. Since only mucosal biopsies are available in microscopic colitis there may be a more common association with lymphocytic venulitis than is currently appreciated.

Clinically, our patient presented with abdominal pain and rectal bleeding, which is the typical presentation of cases with lymphocytic venulitis, ${ }^{3}{ }^{4}$ although colectomy failed to control the bleeding. There was no history of the diarrhoea that is usually associated with lymphocytic and collagenous colitis. ${ }^{510}$ The cause of bleeding in lymphocytic venulitis is usually related to the presence of thrombus resulting in ischaemic ulceration. ${ }^{34}$ Our case did not show any thrombus or ischaemic ulceration although an occlusive myointimal hyperplasia was seen in a few vessels. This has previously been described both in lymphocytic venulitis and in mesenteric vessels from patients with ischaemic colitis. ${ }^{3}$

Lymphocytic colitis has been reported to be associated with arthritis, ${ }^{6}$ coeliac disease, ${ }^{7}$ ulcerative colitis, ${ }^{8}$ and the use of non-steroidal anti-inflammatory drugs and aspirin. ${ }^{11}$ Lymphocytic venulitis, on the other hand, has been seen in association with other forms of colitis, particularly Crohn's disease, ${ }^{12}$ and we have seen it in association with diverticular disease. The two conditions may be causally related rather than being present by mere coincidence. It is of interest that the predominant cell type of the inflammatory infiltrate in both conditions is the $\mathrm{T}$ lymphocyte. It is tempting to speculate that there may be a common stimulus evoking $\mathrm{T}$ cell response such as a drug reaction. Our patient and all those studied by Saraga and Costa $^{4}$ were on antihypertensive drugs.

1 Lie JT. Vasculitis and the gut. I Rheumatol 1991;18:647-9.

2 Wakefield AJ, Sankey EA, Dhillon AP, et al. Granulomatous vasculitis in Crohn's disease. Gastroenterology 1991;100: 1279-87.

3 Flaherty MJ, Lie JT, Haggitt RC. Mesenteric inflammatory veno-occlusive disease. A seldom recognised cause of intestinal ischaemia. Am f Surg Pathol 1994;18:779-84.

4 Saraga EP, Costa J. Idiopathic entero-colic lymphocytic phlebitis. A cause of ischaemic intestinal necrosis. Am $\mathfrak{f}$ phlebitis. A cause of ischaem
Surg Pathol 1989;13:303-8.

5 Veress B, Lofbert R, Bergman L. Microscopic colitis syndrome. Gut 1995;36:880-6.

6 Kingsmore SF, Kingsmore DB, Hall BD, et al. Cooccurrence of collagenous colitis with seronegative spondyloarthropathy: report of a case and literature review. f Rheumatol 1993;20:2153-7.

7 Perisic VN, Kokai G, Pavlovic M. Coeliac disease and collagenous colitis. Ital f Gastroenterol 1992;24:418-20.

8 Giardiello FM, Jackson FW, Lazenby AJ. Metachronous occurrence of collagenous colitis and ulcerative colitis. Gut 1991;32:447-9.

9 Stark ME, Batts KP, Alexander GL. Protein-losing enteropathy with collagenous colitis. Am $\mathcal{F}$ Gastroenterol 1992;87:780-3.

10 Lee E, Schiller LR, Vendrell D, et al. Subepithelial collagen table thickness in colon specimens from patients with microscopic colitis and collagenous colitis. Gastroenterology 1992;103:1790-6.

11 Giardiello FM, Hansen FC, Lazenby AJ, et al. Collagenous colitis in setting of non-steroidal anti inflammatory drugs and antibiotics. Dig Dis Sci 1990;35:257-60. 